\title{
Estimating forage intake and quality in grazing cattle: $A$ reconsideration of the hand-plucking method
}

\author{
MICHIEL F. WALLIS DE VRIES
}

\begin{abstract}
Author was Ph.D. student at the time of the study. Department of Terrestrial Ecology \& Nature Conservation.
\end{abstract} Agric thitural University Wageningen, Bornsesteeg 69, 670S PD Wageningen, The Netherlands.

\begin{abstract}
The hand-plucking method for estimation of bite size and nutritive quality was tested for steers grazing at low stocking rates on heathland and in riverine grassland. Vegetation height, standing crop, and cover of distinct plant categories were determined in 13 sampling periods over 2 years. In each period bite size was estimated with 4 esophageally fistulated steers. Bite counts on different plant categories were made during sampling. The plant categories were sampled separately by hand-plucking and weighed to determine plucking size. Extrusa and handplucked samples were analyzed for concentrations of nitrogen and calcium.

Vegetation height was a more accurate predictor of plucking size than standing crop. A curvilinear relationship was derived between plucking size and bite size. The nutritive quality of extrusa and hand-plucked samples was not significantly different.

It is concluded that the application of the hand-plucking method appears successful when a stratified sampling approach to hand-plucking is followed. Future studies should examine operator-biases and how these can be minimized.
\end{abstract}

Key Words: bite size, diet quality, hand-plucking

Diet selection, food intake, and diet quality of herbivores can be estimated by simulation of the observed diet by hand-plucking. The method is rapid, inexpensive, and simple. It often is the only feasible method to investigate the diet of free-ranging or wild herbivores in heterogeneous environments. Unfortunately, it is subject to a mostly unknown bias as the simulation of the graz-

This paper forms a part of a Ph.D. thess. I would like to thank Prof. H.H.T. Prins. Prof. L. 't Mannet je and 3 anony mour referees for the constructive criticism on the manuseript. Johan Scheele and Teus Bleyenherg. Department of Agronomy, provided invaluable help in tahing care of the tistulated steers. I am furthermore very' much indebted to Maurits Gleichman. Department of Terrestrial Ecology and Nature Consenation, for his great contribution to the field work.

Paper accepted II Nov. 1994. ing animal is likely to be imperfect. The hand-plucking method can be evaluated by comparing hand-plucked estimates of bite size and nutritive quality with data from esophageally fistulated animals.

Fistulated animals are widely used in studies of diet selection, as the extrusa samples offer the opportunity to assess bite size (Forbes 1988) and the botanical composition of the diet (Holechek et al. 1982a). However, biases may arise in the assessment of dietary quality, which limits the use of extrusa to certain constituents. Salivary contamination considerably raises the contents of ash, sodium, and phosphorus so as to preclude any accurate estimation of these constituents in the diet (Holechek et al. 1982b, Langlands 1987). Contents of nitrogen are altered by salivary contamination but do not differ on an organic matter basis (Little 1972, Pinchak et al. 1990). Concentrations of some minerals, calcium in particular, do not appear to be different in extrusa samples (Little 1975, Pinchak et al. 1990). The organic matter digestibility of extrusa samples is generally considered to be similar to the feed on offer, but several experiments have revealed significant differences between the 2 (Langlands 1966, Holechek et al. 1982b. Burritt et al. 1987. Armstrong et al. 1989). Thus, the estimates of dietary quality from extrusa samples are least biased for nitrogen and calcium.

A number of experiments have been conducted to test the handplucking method. Edlefsen et al. (1960) compared the composition of hand-plucked forage with extrusa from esophageally fistulated sheep under range conditions. Differences in nitrogen and cellulose contents were not significant. A number of other constituents (ash, lignin, carbohydrates minus cellulose, gross energy, and phosphorus) were significantly different but this was at least partly due to contamination with saliva. Kiesling et al. (1969) found that hand-plucked samples from one technician contained significantly less silica, ash, protein, ether extract, detergent fiber, and lignin than extrusa samples from steers. Langlands (1974) determined that hand-plucking underestimated digestibility and nitrogen content of sheep diets for low herbage quality and overestimated nutritive quality when herbage quality was high. Also, nutritive quality of hand-plucked samples varied between operators. Van Rees (1984) collected hand-plucked and extrusa samples from 2 steers on 3 consecutive days in high-quality grassland. No significant difference in organic matter digestibility was found between the 2 sample types. Even though 
the nutritive quality of the extrusa samples themselves may sometimes have been biased, these finding suggest that hand-plucking may lead to additional biases in the estimate of dietary quality. Yet, better results might be obtained by careful elaboration of the hand-plucking procedures.

Earlier experiments reported by Wallis de Vries (1990), indicated that hand-plucking underestimated nutritive quality of cattle diets when an average pasture sample of about 100 simulated bites was compared with an extrusa sample. However, a refinement of the method closely predicted diet digestibility. The refinement consisted of sampling different plant categories separately and estimating diet digestibility as a mixture weighted according to bite counts of these categories. This paper presents a more extensive test of the applicability of an elaborated handplucking method to assess both bite size and nutritive quality of cattle diets.

\section{Materials and Methods}

\section{Study Sites}

Grazing trials were conducted in 2 widely different vegetation types in a heathland and a riverine area in the Netherlands. The heathland area, the formerly ungrazed Doorwerthse Heide (50 ha), was dominated by Deschampsia flexuosa and Calluna vulgaris. It was divided into 2 compartments, 1 grazed year-round ( 0.18 steers/ha) and 1 with winter grazing only $(0.23$ steers/ha from December to March). The riverine area, the Renkumse Benedenwaarden, is a river foreland of the Rhine river with a long history of pasture use. The vegetation was dominated by Agrostis stolonifera, Lolium perenne, and Elymus repens. The area was also split into 2 compartments, 1 grazed year-round ( 0.57 steers/ha) and 1 with summer grazing only ( 0.96 steers/ha from April to November).

\section{Experimental Design}

Thirteen experimental periods were planned at 2 month-intervals over 2 years, from May 1989 till May 1991. On each occasion 2 plots of $40 \times 50 \mathrm{~m}^{2}$ were sampled in all 3 currently grazed areas. Sampling plots were fenced with electric wire on the sampling day. Four esophageally fistulated steers (aged ca. 13 months and weighing ca. $300 \mathrm{~kg}$ at the start of the first experiment) were used to collect samples from the selected diet. The animals were allowed to graze the area at least 3 days before experimentation. They were fasted ca. 4 hours prior to sampling to increase their willingness to graze. Samples were caught in a small bucket, with soft plastic wings, strapped to the animal. Food recovery was ensured by fitting a foam plug in the animal's esophagus. However, in 2 steers with a particularly large fistula the plug mostly fell out and was therefore not used in these 2 animals; there was no evidence that this reduced the amount of food recovered. Each extrusa sample (50-250 g dry matter) required 5-10 minutes of grazing. On average 3.2 samples were collected per plot.

Like in most rangelands, the vegetation structure in the sampling plots was heterogeneous. As a result, the extrusa samples consisted of a mixture of bites from short, tall, and flowering ('stemmy') grasses and some other conspicuous species. These plant categories were therefore distinguished (see Table 1) and used for recording biting frequencies and for sampling the avail-
Table 1. Plant categories distinguished on heathland and in riverine grassland.

\begin{tabular}{|c|c|c|}
\hline \multicolumn{3}{|l|}{ Both areas: } \\
\hline Short grass & : & leafy sward $<7 \mathrm{~cm}$ high \\
\hline Tall grass & : & leaty sward $>7 \mathrm{~cm}$ high \\
\hline Stemmy grass & : & sward with $>2$ nowering stems/dm² \\
\hline \multicolumn{3}{|l|}{ Heathland only: } \\
\hline Short Molinia & : & Molinia caerulea $<20 \mathrm{~cm}$ high \\
\hline Tall Molinia & : & Molinia caerulea $>20 \mathrm{~cm}$ high \\
\hline Other grasses & : & Various short broad-leaved graminoids \\
\hline Short Callma & : & Calluna vulgaris $<20 \mathrm{~cm}$ high \\
\hline Tall Calluna & : & Calluma vulgaris $>20 \mathrm{~cm}$ high \\
\hline Erica & : & Evica tetralix \\
\hline \multicolumn{3}{|c|}{ Riverine grassland only: } \\
\hline Phalaris & : & Phalaris arundinacea \\
\hline Buttomis & : & Butomus umbellatus \\
\hline Cirsium & : & Cirsium anense \\
\hline Rumex & : & Rumer obtusifolius $+R$. crispus \\
\hline
\end{tabular}

able forage. The plant categories were sampled by hand-plucking (50-100 pickings for each category) by the same person over the entire experiment. The samples were plucked between the thumb and a backward-bent forefinger, simulating the steers' grazing as closely as possible. The grazing behavior of the animals was observed during sample collection after prior familiarization, using the OBSERVER 2.0 computer programme (Noldus 1991). These data provided a weighted estimate of average bite size and nutritive quality for the extrusa samples, which could be compared with the measured values as explained below.

In each experimental period the vegetation height and available standing crop for the 3 grass categories (i.e. short, tall, and stemmy grass) were measured on 50 points within 2 (riverine grassland) or 3 (heathland) plots, including the sampling plots for the fistulated steers. The 50 points were laid out systematically in 5 equidistant lines, with 1 point every 5 meters. At every point the plant category was recorded and vegetation height was measured with a tempex disc (ca. $8 \mathrm{~g}, 10 \mathrm{~cm}$ diameter) which was gently lowered onto the vegetation along a measuring-rod. The standing crop was sampled every filth point by clipping an area of $25 \times 25$ $\mathrm{cm}^{2}$ from a single grass category down to a height of $2 \mathrm{~cm}$ or to the level of litter and dead plant material. At least 4 samples were clipped for each grass category (not enough stemmy grass was available for clipping in May 1991 on heathland).

\section{Sample Analyses}

The samples were stored in polythene bags at $-20^{\circ} \mathrm{C}$. Extrusa samples were first freeze-dried to prevent Maillard browning reactions, whereas hand-plucked and standing crop samples were oven-dried in a force-draught oven at $65^{\circ} \mathrm{C}$. All samples were weighed to determine respectively average bite size per sample (total number of bites divided by sample dry weight), plucking size or standing crop. Due to a limited processing capacity, samples from only 1 full year (6 periods: May, July, September, and November 1989, and January and May 1990) were selected for chemical analysis. After grinding through a $1 \mathrm{~mm}$ sieve the extrusa and hand-plucked samples were analyzed for concentrations of total nitrogen ( $\mathrm{N}$ on organic matter basis) and calcium (Ca on dry matter basis) to provide an estimate of nutritive quality according to Walinga et al. (1989). $\mathrm{N}$ and $\mathrm{Ca}$ were chosen 
because these constituents appear to be least affected by salivary contamination.

\section{Data Analysis}

The data were pooled for the different vegetation types and compartments within the heathland and the riverine area, as these produced similar results. Since both areas differed widely in vegetation height and plant texture, which could influence the relation between plucking size and bite size, the data for heathland and riverine grassland were analyzed separately with respect to these parameters. Data on nutritive quality on the other hand, were pooled for both areas. This offered the possibility to extend the comparison between grazed and hand-plucked samples over a wider range of nutrient content. Moreover, there was no reason to assume that the comparison would differ between areas. All statistical analyses were carried out with the SAS (1985) computer package. Regression analysis was conducted to determine the effect of vegetation height and standing crop on plucking size.

Bite size was expressed relative to an estimated biting area to account for animal growth during the experiment. Biting area was chosen because it represents a crucial interface between the animal and the forage (Illius and Gordon 1987). It was calculated as a circle with the diameter of the incisor arcade breadth. This appears to be a realistic assumption for grassland vegetation of medium height (Illius 1989). The arcade breadth of the fistulated animals (measured in late April of 1989 to 1991) increased linearly with live weight, although individual variation was apparent (Fig. 1). This relation allowed a separate estimation of arcade breadth for each individual on the basis of live weight, which was measured at each sampling period. An average plucking size corresponding to each extrusa sample was calculated by a weighted mean of plucking size for the different plant categories in accordance to their proportion in the bite count. The sample values and sample estimates of the different animals were averaged to give one data pair per plot. Regression analysis was carried out for both vegetation types separately to determine the relation between plucking size and bite size. The regression line was forced through the origin, as it was assumed that cattle bite size and plucking size are 0 under similar conditions.

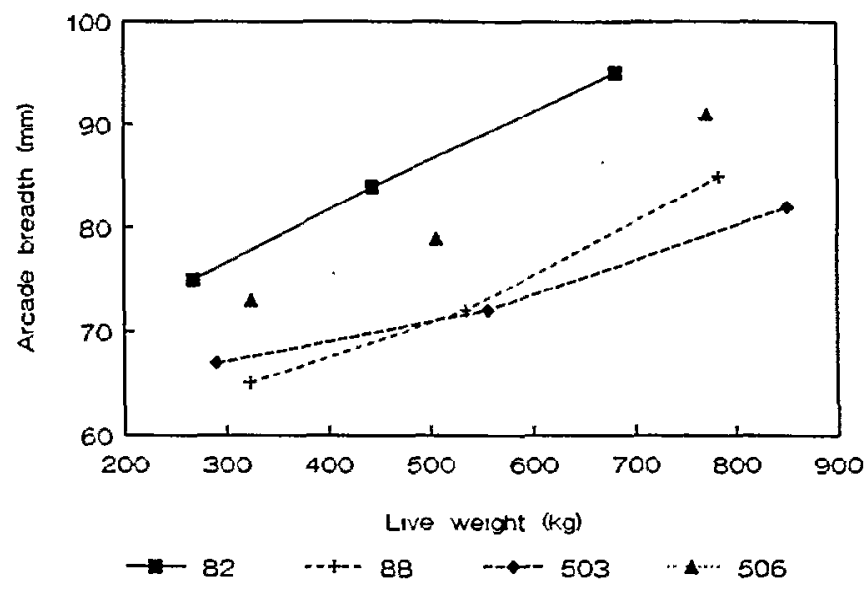

Fig. 1. Incisor arcade breadth as a function of live weight in 4 esophageally fistulated steers (numbered $82,88,503$, and 506).
In order to assess a possible bias in the estimate of nutritive quality by hand-plucking, plot averages for the nutritive quality of extrusa samples and their estimates from hand-plucked samples were compared by regression analysis. The estimate of the nutritive quality of an extrusa sample based on hand-plucked samples was calculated as follows:

$$
\% N Q=\Sigma\left(N_{i} B S_{i} \% N Q_{j}\right) / \Sigma\left(N_{i} B S_{i}\right)
$$

where

$$
\begin{aligned}
\% \mathrm{NQ}_{\mathrm{i}}= & \begin{array}{l}
\text { nutritive quality }(\mathrm{N} \text { or } \mathrm{Ca} \text { ) of plant category } \mathrm{i} \\
\text { (in \% of dry matter) }
\end{array} \\
\mathrm{Ni}= & \text { the number of bites on plant category } \mathrm{i} \\
\mathrm{BS}_{\mathrm{i}}= & \begin{array}{l}
\text { bite size of plant category } \mathrm{i} \text { (estimated from } \\
\text { regression equation of bite size on plucking } \\
\text { size) (in } \left.\mathrm{mg} / \mathrm{cm}^{2}\right)
\end{array}
\end{aligned}
$$

\section{Results}

\section{Standing Crop and Vegetation Height of Plant Categories}

Standing crop and vegetation height were generally lower on heathland than in the riverine area (Table 2), especially during the growing season. Vegetation height and standing crop showed high linear correlation coefficients in both heathland $(r=0.866$, d.f. $=48, P<0.001)$ and riverine grassland $(\mathrm{r}=0.921$, d.f. $=96, P$ $<0.001$ ). The variation in plucking size, however, was better explained by vegetation height than by standing crop (Table 3 ). Due to the strong correlation between height and standing crop the bulk density (i.e. standing crop divided by height) did not show any significant correlation with plucking size.

\section{Bite Size Estimation}

The regression analysis revealed a close fit for a curvilinear relation between plucking size (PS, g; with $95 \%$ confidence intervals for parameters) and bite size per unit biting area (BS, $\mathrm{mg} / \mathrm{cm}^{2}$ ) (Fig. 2):

$$
\begin{aligned}
& \text { Heathland: } \mathrm{BS}=47.98( \pm 8.11) \mathrm{PS}-28.39( \pm 17.17) \mathrm{PS}^{2} \\
& \mathrm{R}^{2}=0.779, \text { d.f. }=22, P<0.001 \\
& \text { Riverine: } \mathrm{BS}=34.87( \pm 4.48) \mathrm{PS}-17.53( \pm 7.57) \mathrm{PS}^{2} \\
& \mathrm{R}^{2}=0.803 \text {, d.f. }=26, P<0.001
\end{aligned}
$$

The quadratic term in the regression equation was significant for both heathland and riverine grassland $(P<0.01$ and $P<0.001$

Table 2. Average and range (minimum-maximum) for standing crop and vegetation height from different plant categories on heathland (Deschampsia flexuosa type) and in riverine grassland (Lolium perenne type) over 13 study periods in 1989-1991. Differences in standing crop and vegetation height between plant categories were significant $(P<0.05)$ in all periods.

\begin{tabular}{lcc}
\hline \hline & \multicolumn{1}{c}{ Standing crop } & \multicolumn{1}{c}{ Vegetation height } \\
\hline & $\left(\mathrm{g} / \mathrm{m}^{2}\right)$ & $(\mathrm{cm})$ \\
Heathland & & $5.2 r(3.96 .0)$ \\
Short grass & $87.6(58.1-114.3)$ & $9.6(8.6-10.8)$ \\
Tall grass & $187.8(146.3-266.1)$ & $15.8(12.8-19.5)$ \\
Stemmy grass & $297.4(186.5-406.7)$ & \\
Riverine grassland & & $5.3(4.0-6.2)$ \\
Short grass & $110.1(64.0-198.7)$ & $13.1(8.4-25.5)$ \\
Tall grass & $246.5(130.6-498.4)$ & $18.6(6.0-35.9)$ \\
Stemmy grass & $364.2(157.2-691.5)$ &
\end{tabular}


Heathland

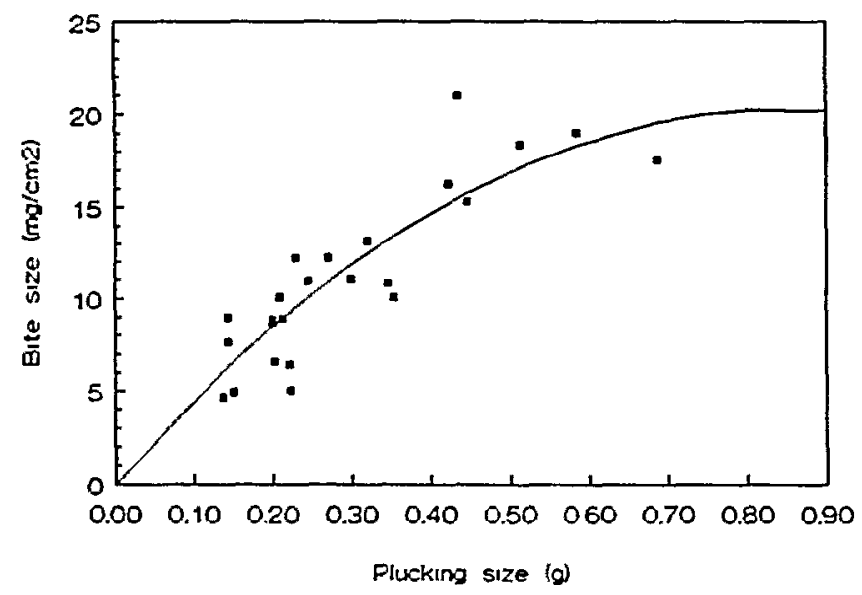

Riverıne grassland

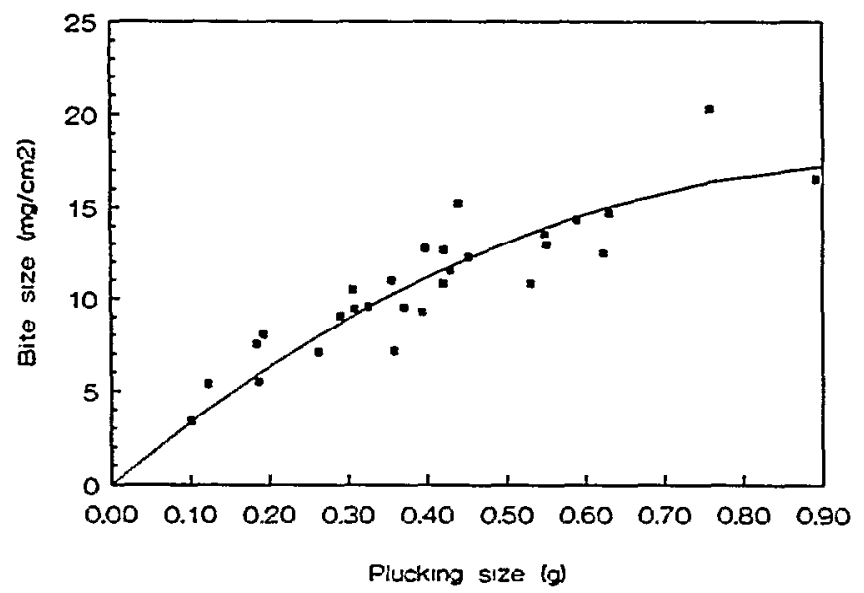

Fig. 2. Bite size per unit biting area of esophageally fistulated steers in relation to plucking size on a) heathland and b) riverine grassland (dots represent plot means, the line shows the regression equation given in the text).

respectively). Without the quadratic term the explained variation decreased respectively to $66.1 \%$ and $63.1 \%$.

\section{Nutritive Quality}

The estimated contents of nitrogen and calcium (with $95 \%$ confidence intervals for parameters) were similar to the contents in the diet selected by the fistulated steers (Fig. 3):

$$
\begin{aligned}
\mathrm{N} \text {-diet }=0.97( \pm 0.20) \mathrm{N} \text {-est. }+0.11( \pm 0.51) \\
\mathrm{R}^{2}=0.751, \text { d.f. }=30, P<0.0001 \\
\text { Ca-diet }=1.14( \pm 0.14) \text { Ca-est. }-0.04( \pm 0.06) \\
\mathrm{R}^{2}=0.906 \text {, d.f. }=29, P<0.0001
\end{aligned}
$$

For both regressions the intercept was not significantly different from $0(P>0.05)$ and the regression coefficients were not significantly different from unity $(P>0.05)$. Therefore, the estimate of nutritive quality by hand-plucking showed no significant bias.

Table 3. Regression equations describing the relation between plucking size ( $\mathrm{PS}, \mathrm{g})$ and vegetation height $(\mathrm{H}, \mathrm{cm})$, and between plucking size and standing crop (SC, $g / \mathrm{m}^{2}$ ) for Deschampsia flexuosa-vegetation on heathland and for riverine grassland $(95 \%$ confidence intervals for parameters indicated befween brackets).

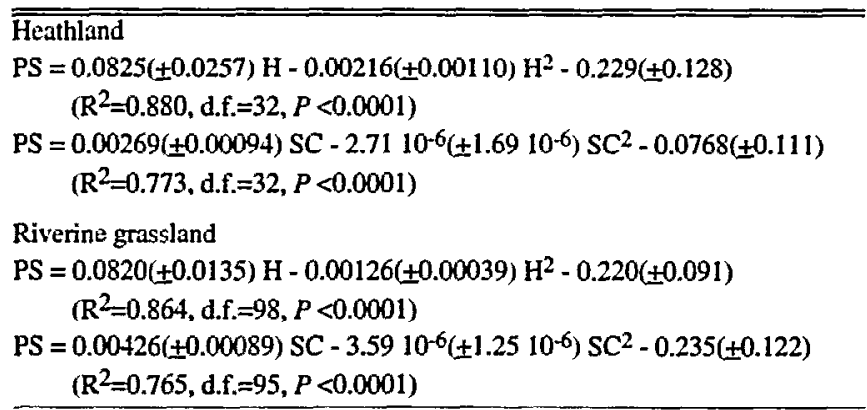

\section{Discussion}

\section{General Remarks}

The results of this experiment show that hand-plucking can be used as a method to assess bite size and diet quality. This contrasts the findings of Kiesling et al. (1969) and Langlands (1974). The applicability of the hand-plucking method relies on sub-sampling of different plant categories and recording bite counts to adjust for diet selection, rather than taking a mixed sample of different plant categories. Furthermore, extensive familiarity with the grazing habits of the animal is a prerequisite. In this respect, cattle will be easier to simulate than sheep, which are more selective grazers (Grant et al. 1985 and 1987). This may have proved a handicap in the experiment by Langlands (1974). This author also pointed to the problem of differences between operators. This aspect was not tested in the present study as the data were collected by one person only. However, calibration of the estimation of bite size and diet quality is advisable whenever possible, especially in heterogeneous vegetation.

\section{Vegetation Structure Versus Botanical Composition for the Estimation of Diet Selection}

Within a certain study area, the botanical composition needs to be taken into account to differentiate between vegetation types. Within a botanically defined grassland type, distinction of the 3 plant categories on the basis of vegetation structure-short, tall, and stemmy grass-appears a useful and practical method to quantify diet selection. It may seem more appropriate to distinguish separate plant species, even within a grassland type. This is probably true in cases where species are easily distinguished and present clear differences in nutritive quality, such as in arid range with low vegetation cover. However, in dense grassland swards the estimation of bite size would become much more difficult 

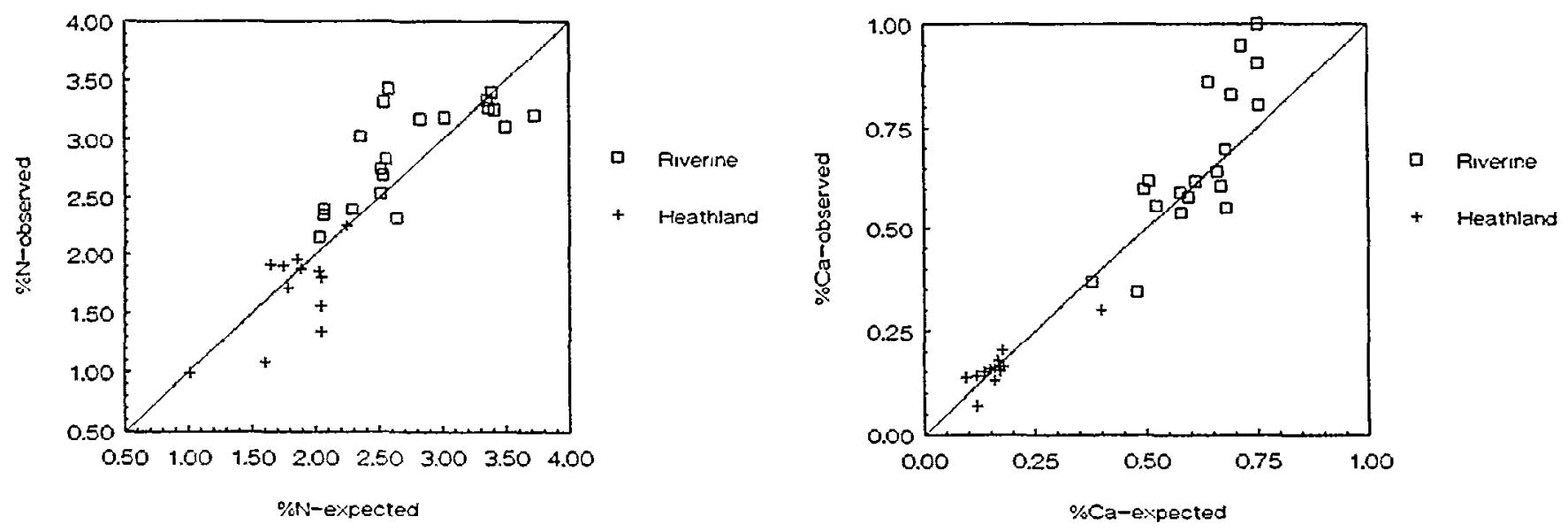

Fig. 3. Comparison of diet quality as estimated by hand-plucking (expected) and as determined in extrusa samples from esophageally fistulated steers (observed) for a) nitrogen $(\mathrm{N})$ and $\mathrm{b}$ ) calcium (Ca). Dots represent plot means from heathland and riverine grassland. The line shows the values for equality of observed and expected values.

with bite counts on a species basis. In addition, the difference in nutritive quality between grasses of different growth stage is of the same magnitude as between different grass species on the same site (Hacker and Minson 1981. Ulyatt 1981, Norton 1982, Koorevaar 1986). Distinction hetween species would therefore not necessarily result in a more accurate estimate of diet quality. This supposition was not specifically tested in this study, but some inferences can be made from additional data. In the riverine area. changes in botanical composition between years were significant for Elymus repens and Agrostis stolonifera (Wallis de Vries, unpubl.). Yet, there was no significant correlation between the cover of either of these species and changes in nutritive quality for nitrogen, phosphorus, calcium, sodium, and organic matter digestibility. In contrast, an ANOVA revealed a significant difference between grass categories for all 5 nutrients examined $(P<0.05$, although the difference for calcium was only marginal: $P<0.10$ ). Thus, the distinction of grass categories appears more important than the differentiation between species. A practical argument in favor of the present approach is that cattle do not appear to discriminate actively between grassland species growing in a fine mixture (Grant et al., 1985). It certainly is difficult for the observer to distinguish individual plant selection.

Extrapolation of the regression equations of bite size versus plucking size and plucking size versus vegetation height reveals a curvilinear increase of bite size with vegetation height (Fig. 4). The relationship is markedly similar for heathland and riverine grassland. This further emphasizes the impact of vegetation structure on bite size and indicates the possibility to estimate bite size from vegetation height.

\section{Cunvilinearity between Plucking Size and Bite Size}

The relation between plucking size and bite size found in this study was curvilinear. It may be argued that this type of relation could have a more general applicability. The curvilinearity results mainly from the choice of 0 intercept. This seems justifiable on the ground that the allometric coefficient for bite weight declines on very short swards (Illius 1989). The ability of cattle and a hand-plucking human to harvest grass then would converge, and it seems a fair assumption that the point of a 0 harvest would be reached at a similar sward height (ca. $3 \mathrm{~cm}$ when extrapolating the regression between vegetation height and plucking size). Converscly, with increasing herbage availability cattle would tend to take relatively larger bites, favored by the broader dental arcade and an extension of the reach by a sweep of the tongue, in comparison to the relatively small span of around half the size of a forefinger. With a further increase in sward height, selectivity and a decrease in bulk density would become of greater importance, leading to a smaller bite size (Forbes 1988) and, hence, a convergence of bite size and plucking size. The calibration of plucking size is more important for an accurate estimate of intake than for the assessment of nutritive quality. When plucking size instead of estimated bite size was used the additional error in the estimate of nitrogen or calcium content was less than $5 \%$, suggesting that pluck size may be used directly with little effect on the nutritive estimate.

\section{Conclusion}

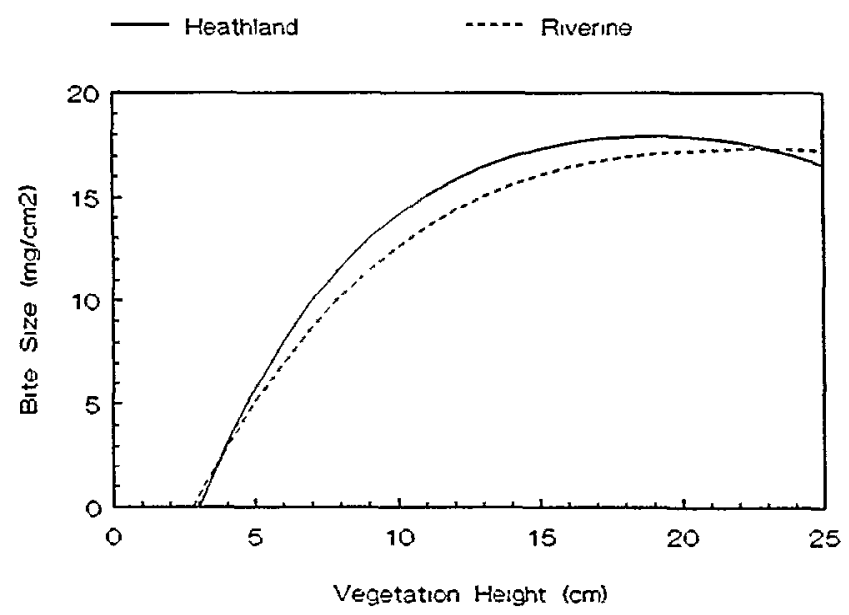

Fig. 4. Bite size in relation to vegetation height in heathland and riverine grassland, as extrapolated from the regression equations hetween plucking size and vegetation height and between bite size and plucking size. 
The hand-plucking method offers potential for determining bite size and nutritive quality of grazing herbivores. The incorporation of stratified sampling of different plant categories in combination with observations on the selection between categories appears an essential improvement. The method should prove especially valuable in heterogeneous and sparsely grazed vegetation, where animals can demonstrate great selectivity. Moreover, hand-plucked samples are free from the contaminants precluding reliable analyses for a number of parameters for nutritive quality in esophageal extrusa or rumen samples. However, the method relies heavily on a calibration between operators and the study animal. Future studies should investigate the variation between operators and its minimization through the development of standard procedures.

\section{Literature Cited}

Armstrong, R.H., T.G. Common, and G.J. Davies 1989. The prediction of the in vivo digestibility of the diet of sheep and cattle grazing indigenous hill plant communities by in vitro digestion, faecal nitrogen concentration or 'indigestible' acid-detergent fibre. Grass and Forage Sci. 44:303-313.

Burritt, E.A., J.C. Malechek, and F.D. Provenza 1987. Changes in concentrations of tannins, total phenolics, crude protein, and in vitro digestibility of browse due to mastication and insalivation by cattle. J. Range Manage. 40:409-411.

Edlefsen, J.L., C.W. Cook and J.T. Blake 1960. Nutrient content as determined by hand-plucked and esophageal fistula samples. J. Anim. Sci. 19:560-567.

Forbes, T.D.A. 1988. Researching the plant-animal interface: the investigation of ingestive behavior in grazing animals. J. Anim. Sci. 66:2369-2379.

Grant, S.A., D.E. Suchling, H.K. Smith, L. Torvell, T.D.A. Forbes and J. Hodgson 1985. Comparative studies of the diet selection by sheep and cattle: the hill grasslands. J. Ecol. 73:987-1004.

Grant, S.A., L. Torvell, H.K. Smith, D.E. Suckling, T.D.A. Forbes and J. Hodgson 1987. Comparative studies of the diet selection by sheep and cattle: blanket bog and heather moor. J. Ecol. 75:947-960.

Hacker, J.B. and D.J. Minson 1981. The digestibility of plant parts. Herb. Abstr. 51:459-482.

Holechek, J.L., M. Vavra and R.D. Pieper 1982a. Botanical composition determination of range herbivore diets: a review. J. Range Manage. 35:309-315.

Holechek, J.L., M. Vavra and R.D. Pieper 1982b. Methods for determining the nutritive quality of range numinant diets: a review. J. Anim. Sci. $54: 363-376$.

Illius, A.W. 1989. Allometry of food intake and grazing behaviour with body size in cattle. J. Agric. Sci., Camb. 113:259-266.

Illius, A.W. and I.J. Gordon (1987). The allometry of food intake in grazing ruminants. J. Anim. Ecol. 56:989-999.

Kiesling, H.E., A.B. Nelson and C.H. Herbel 1969. Chemical composition of Tobosa grass collected by hand-plucking and esophageal-fistulated steers. J. Range Manage. 22:155-159.

Koorevaar, H. 1986. Produktie en voederwaarde van gras bij gebruiksen bemestingsheperkingen voor natuurbeheer. Doctoral thesis. Agr. Univ. Wageningen, The Netherlands.
Langlands, J.P. 1966. Studies on the nutritive value of the diet selected by grazing sheep. I. Differences in composition between herbage consumed and material collected from oesophageal fistulae. Anim. Prod. 8:253-259.

Langlands, J.P. 1974. Studies on the nutritive value of the diet selected by grazing sheep. VII. A note on hand-plucking as a technique for estimating dietary composition. Anim. Prod. 19:249-252.

Langlands, J.L. 1987. Assessing the nutrient status of herbivores. In: the nutrition of herbivores. (J.B. Hacker and J.H. Ternouth eds), pp.363-390. Academic Press, Sydney.

Little, D.A. 1972. Studies on cattle with oesophageal fistulae: The relation of the chemical composition of feed to that of the extruded bolus. Austr. J. Exp. Agr. Anim. Husb. 12:126-130.

Little, D.A. 1975. Studies on cattle with oesophageal fistulae: Comparison of concentrations of mineral nutrients in feeds and boluses. Austr. J. Exp. Agr.. Anim. Husb. 15:437-439.

Noldus, L.P.J.J. 1991. The Observer: a software system for collection and analysis of observational data. Behav. Res. Meth. Instr. Comp. 23:415-429.

Norton, B.W. 1982. Differences between species in forage quality. In: Nutritional limits to animal production from pastures. (J.B. Hacker ed.), pp.89-110. CAB, Farnham Royal, UK.

Pinchak, W.E., L.W. Greene and L.J. Ilunt 1990. Biases in relative estimates of dietary mineral status from esophageal extrusa. J. Range Manage. 43:136-138. SAS 1985.

SAS User's Guide. Version 5 edition. Cary, N.C.

Ulyatt, M.J. 1981. The feeding value of temperate pastures. In: Grazing animals. (F.H.W. Morley ed.), pp.125-141. Elsevier, Amsterdam.

Van Rees, H. 1984. The behaviour and diet of free-ranging cattle on the Bogong High Plains, Victoria. Ph.D. Thesis. Univ. of Melbourne.

Walinga, I., WW. van Vark, V.J.G. Houba and J.J. van der Lee 1989. Soil and plant analysis: 7. Plant analysis procedures. Department of Soil and Plant Nutrition. Agr. Univ. Wageningen, The Netherlands.

Wallis de Vries, M.F. 1990. An evaluation of the hand-plucking method to assess the digestibility of cattle diets. Proc. VIIth European Grazing Workshop, Wageningen, The Netherlands. 